\title{
The Study of Corpus-based Interpreting Teaching from the Perspective of Eco- Translatology
}

\author{
Sheng-bai Chen \\ Hunan First Normal UniversityChangsha, China \\ Shirly01@163.com
}

\begin{abstract}
Eco-translatology not only improves the interpreting theories and practice but also acts as the guideline to the interpreting teaching. Therefore, this paper attempts to put forwards the implications for the improvement of interpreting teaching from the perspective of Eco-translatology, and explore the strategies and suggestions to enhance the quality and efficiency of corpus-based interpreting teaching in order to bring the fresh content to the study of interpretation and open up the new horizon in the field of interpretation.
\end{abstract}

Keywords-eco-translatology; corpus-based; interpretation teaching;

\section{INTRODUCTION}

The characteristics of interpretation reflect that interpreting teaching is different from other language teaching and its teaching method should fully embody the nature and features of interpretation. Only when interpreting teacher takes into account the characteristics of interpretation and attaches an importance to the actual situation and needs of students, will interpreting teaching achieve the better effect.

Interpreting teaching is not the counterpart of translation teaching and continuity of linguistic teaching. The aim of corpus-based interpreting teaching is to make students bear the basic qualities of the competent interpreter, and to let them carry out the effective and cross-cultural communication making use of the verbal and non-verbal ways. From the perspective of eco-translatology, interpretation regarded essentially as "a selection activity of the interpreter's adaptation to fit the eco-environment of interpreting", the process of interpretation is the production of a target rendition through the interpreter's adaptation to a specific interpretational eco-environment and the interpreter's selection of both the degree of adaptation and the phrasing of the final target rendition; the interpreting principle is briefly summarized as multi-dimensional adaptations and adaptive selections, and the interpreting methods are generalized as three-dimensional transformations(i.e., linguistic, cultural and communicative dimensions).[1] Therefore, Translation as Adaptation and Selection, as the core theory of eco-translatology, is also the theoretical basis of corpus-based interpreting teaching.

\section{NEW MODEL OF CORPUS-BASED INTERPRETING TEACHING}

Based on the Translation as Adaptation and Selection and the rich teaching experience, the author puts forward the new model of corpus-based interpreting teaching, which mainly includes the introduction of interpreting theories; the training of interpreting skills; the cultivation of the intercultural awareness of students; the development of the communicative competence of students; the extracurricular practices. In order to clearly illustrate the relationship among several aspects, the author designed the following diagram and the relationship among five teaching links is illustrated as figure 1 .

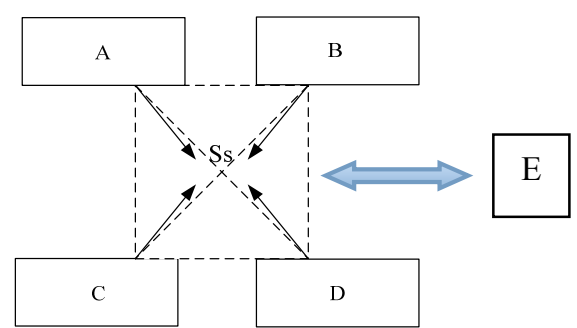

Figure 1. The Model of Corpus-based Interpreting Teaching.

According to this figure, the five teaching links in this new model of corpus-based interpreting teaching is closely connected and depends on one another. In this figure, A represents the introduction of interpreting theories, B stands the training of interpreting skills, $\mathrm{C}$ represents the cultivation the intercultural awareness of students, D stands the development the communicative competence of students and E represents the extracurricular practices. During the practice of corpus-based interpreting teaching, the student is the center of this series of teaching links, and teacher should fully reflect the importance of these teaching respects, and organically organize these parts through teaching materials and classroom practices.

In light of the characteristics of interpreting from the perspective of eco-translatology, author puts forward that interpreting teacher should create the interpretational ecoenvironment in the classroom. At the beginning of the implementation of corpus-based interpreting teaching, teacher should introduce the interpreting theory which is the basis of interpreting practice. Then, teacher should instructor the interpreting skills in a concrete way, emphasis should be laid on the training of the listening comprehension, the training of improving memory competence and the training of expression. In terms of interpreter' $\mathrm{s}$ adaptation and selection to competence, stresses should lay on cultivating students' intercultural awareness and developing students' communicative competence. Finally, So as to enhance the 
teaching quality and the proficiency of the students' interpreting skills, teacher should skillfully organize the extracurricular activities based on the interpreting corpus.

\section{TRAINING OF INTERPRETING SKILLS BASED ON ECO- TRANSLATOLOGY}

At the linguistic level, the principles for interpreting are "multi-dimensional adaptations and adaptive selections", while the interpretational methods are "three dimensional transformations" - linguistic, cultural, and communicative dimensions.[2] In the interpretational eco-environment, interpreter should consider the linguistic dimensional adaptations and adaptive selections and have the high degree of the bi-linguistic competence. Therefore, what is the most important in the corpus-based interpreting teaching is to improve students' linguistic proficiency and interpreting skills. So the interpreting teacher should attach an importance to the trainings of listening, memory, note-taking and expression.

\section{A. $\quad$ Training of Listening in Interpreting}

Due to its feature of interpreting, compared with the general listening, listening in interpreting is a more complicated and difficult process. As Seleskovitch expresses it, listening for sense is the key to all modes of interpreting.[3] There are a number of different ways in which the listener can process or fail to process---incoming speech in interpreting, which could serve as a basis for evaluating the success of a particular listening performance.

Teacher should help the students learn to listen for sense. The teacher should tell students that interpreter must learn practically to disregard the words he hears in order to pay full attention to the message. When the purpose is to have the students practice listening for sense, the length of the passages and the teacher's instructions and feedback are all geared to this specific objective. At the beginning, listening for sense includes having the students listen to an everyday magazine article on some current event and then asking them to give back the main points in a coherent way. Then teacher asks questions about the content of the text in order to steer the students' concentration away from any words based on the interpreting corpus.

Teacher should let the students listen to different accents. At the international conferences, the interpreter must understand the accents of various English-speaking countries and regions, and a wide variety of non-native speakers. Therefore, based on the interpreting corpus, the teacher should try his /her best to use recordings of discussions in international meetings and other authentic listening materials with various accents to expose the students to and familiarize the students to some of the different accents they will later encounter. Last but not least, teacher should help student form good listening habits.

\section{B. Training of Memory Competence}

In interpreting, memory and understanding are inseparable and dependent on each other. Therefore, memory in interpreting only consists of understanding the meaning that the words convey. Thus, what is the most important is that the teacher should let the students know good and extraordinary memory is not to remember the form of the message (sounds, figures, words and texts) but to wholly comprehend the message and grasp the meaning the message conveyed. To reach this aim, based on the interpreting corpus, the teacher may use the source and target language rehearsal exercises in the classroom. The teacher chooses the materials with various styles and let them listen to one of them in the class. After hearing a passage the students are asked to retell the main points of the passage with the source language. A period of this training later, the teacher can begin the target language rehearsal exercises based on the interpreting corpus. At this stage, the students practice retelling the gist of the message with the target language after hearing a message, basing their rehearsal on the sense presented and not on the words used to express them.

Logical reasoning exercises. The purpose of this kind of exercises is to train students' logical reasoning competence which facilitates the much better memory. The teacher gives the students some incoherent and unordered messages or passages and asks them to change them into some coherent and logical messages or passages based on the interpreting corpus.

Visualization exercises. The aim of this type of exercises is to help the students focus on sense instead of concerning on the words and evoke images from the message to get a clear picture and memorize it more easily. At the initial stage, the students find it difficult and hard to master. So the teacher should encourage the students do a lot of visualization exercises based on the interpreting corpus, and the students gradually tend to disregard the form of the message and picture images instead to help them memorize.

\section{Training of Note-taking}

Notes serves as memory devices and aids which triggers the memory of what was understood. In brief, notes serve as a "reminder" or a "springboard". In the class, firstly the teacher should explain what to note for the students. The author also believes that the teacher should let the students pay more attention to the following aspects: (1) Notes should be written down what the interpreter intends to say in the target language; (2) Notes should be clear and legible enough to be grasped at a glance, with symbols for the beginning and the end; (3) Notes should be written down as little as possible because too many notes result in the interpreter's confusion and distraction. In final, based on the interpreting corpus, author holds that when proceeding from memory exercises to simple note taking to longer and more complex messages, besides the above requirements, the students were required to develop their own system of note-taking.

\section{Training of Re-expression}

Hugengshen (2011) pointed out that interpreting is to produce target-language discourse through the interpreter' $s$ adaptation to the interpretational eco-environment. Reexpression stage in interpreting process involves trans-code between SL and TL according to the interpreting standardfaithfulness and expressiveness and instantaneousness. Due to the limited time, during the re-expression stage, 
interpreters must comprehend, record and re-express the source speech as soon as possible rather than making the audience wait for a long time. In this case, related skills must be trained and attained to ensure the quality of interpretation. In the practical teaching, teacher consciously should ask students to get rid of the linguistic structure and interpret the original meaning in an accurate way. Meanwhile, teacher should guide the students to participate in various forms of imitation training in order to learn some idiomatic structure of the sentences, paragraphs and chapters based on the interpreting corpus. What' $s$ more, teachers can ask students to recite some good English essay of a number of different topics and themes and let students to analyze how to organize the discourse so as to learn some techniques of expression. In this teaching link, the expression of the target language should not be limited to imitation, should also include bilingual conversion, public speaking skills, paraphrasing and role-playing etc..

\section{Cultivation OF StUdents' InTERCUltural AWARENESS BASED ON ECO-TRANSLATOLOGY}

Based on eco-translatology, an interpreter needs to take cultural factors into consideration when interpreting, due to the target audience's perception and acceptance of the source text. As we know, interpreting is a peculiar type of intercultural communication, involving two linguistically different cultures, intercultural awareness here refers to the interpreter's perception of the cultural elements of the language involved in the process of interpreting.

Teacher should use case method. The definition of a teaching case varies as does its application in the classroom. The advantage of case method is to present students with real, unfiltered situation and let students use observations and reflections to naturally form abstract generalizations that they can in turn apply to new situations. Introducing case method to cultivate students' intercultural awareness in class is just to guide students to gain a good knowledge of how cultural differences influence the interpreting and grasp the principles to deal with the cultural differences in interpreting.

Based on the interpreting corpus, teacher should use video films, radio and TV programs and selected recordings in class and follow it up with discussion. Through carefully planned questioning, the teacher leads the students to an understanding of the values held by the people of a foreign culture while watching video films. After viewing, the teacher divides the class into several groups and asks the students to compare notes and exchange ideas. Then, a representative of each group gives a short presentation to the whole class. Through this approach, the teacher can help students gain the cultural information and increase their intercultural awareness.

Teacher should invite casual foreign visitors to class. The foreign visitors can give some lectures on their local areas, language and customs in which students have more interests. Through the free and relaxed discussions, the students are apt to pick up some cultural information they would not be able to get otherwise. At the same time, the teacher can ask the students to make comparisons the habits, customs and values of the Chinese with those of other foreign people so as to enhance their cultural sensitivity and bridge the cultural gap.

\section{DEVElopment Of Students' COMMUNiCATIVE COMPETENCE BASED ON ECO-TRANSLATOLOGY}

In light of eco-translatology, transformation of adaptive selection of communicative intent in interpretation process, interpreter should also focus on the selective transformation communication level and make sure that communicative intent of the source speech can embodied in the target rendition. As we know, interpreting is the peculiar communicative activity, and the basic task of interpreter is to facilitate communicative parts to effectively communicate. Hence, for purpose of developing students' communicative competence in the interpreting course, author puts forward the following suggestions.

In the interpreting course, the emphasis is laid both on the acquisition of language and interpreting skills and on the acquisition of communicative competence. As a result, teacher should make use of the "learner-centered" approach which puts the learner in the center of the learning process in class. That is to say, teacher should concisely talk for a short period and provide students with more opportunities to practice. Moreover, the teacher should promote the communication and exchange between the teachers and students.

Meanwhile, the teacher should be aware to lay stress on the role of non-verbal communication. Non-verbal communication mainly includes three areas: temporal behavior, spatial behavior and body language. In daily life, people achieve some communicative purpose through a lot of non-verbal communication, such as gestures, facial expressions, eye contact, tone of voice, appearance, etc. According to Eakins (1982), 70 percent of meanings communicates in human interactions are carried by nonverbal other than verbal signs.[4] As a result, firstly, the teacher should let students learn to keep eye contacts with the speaker and pay more attention to gestures of the speaker, which facilitates comprehension. Then, the teacher should help students learn to adjust their tone of voice and control their speaking speed. Steadily, under the teacher's guidance, students will form good speaking habits and the proper manners in interpreting. In final, students will spontaneously attach an importance to the nonverbal communication so as to realize the effective communication in interpreting. At the same time, it is an important task for the teacher to create the active, pleasant and free class atmosphere favorable to enhance students' communicative competence. By doing this, students will become more confident and form good psychological qualities.

\section{EXTRACURRICULAR ACTIVITIES BASED ON ECO- TRANSLATOLOGY}

According to eco-translatology, translation is the translator's selection and adaptation in the translational ecoenvironment, which comprises the worlds of the source text, the source and target languages, the linguistic and cultural aspects of translating, and the people involved. It is self- 
evident that practice in the proper eco-environment makes good interpreting. In the other words, an excellent interpreter must undergo a process of intensive training. However, students' practice in the interpreting course is far from enough. How to deal with this kind of situation is a difficult problem for us. Enriching the extracurricular activities is an effective way. Extracurricular activities are the necessary supplement of the class instruction. As a result, the interpreting teacher should try to organize diversiform extracurricular activities based on the interpreting corpus.

Public lectures given by interpreting scholars or experts are very necessary.[5] The teacher may invite scholars and experts to give students lectures on some topics, such as the theory of interpreting, the features of interpreting, interpreter's professional ethics and culture and interpretation etc. As long as students gain a good of knowledge of interpreting, they can better integrate theory with practice. Teacher can implement some impromptu oration contests and virtual interpreting contests. Before the teacher organizes these activities, he/she must do a lot of preparation and arrangement in order to reach the predetermination aim. These activities are easy to liven up the atmosphere and force students into the real state so that students can accumulate practical experience and form confidence in themselves. Practice in the real context, such as the activities of foreign affairs in the university, interview with the foreign visiting scholar and seminar with the foreign university, etc. The teacher may provide these good opportunities to the students as possible as he/she can. These activities help students both form good psychological qualities and widen their field of vision.

\section{SUMMARY}

Sum up, this paper tentatively gives some implications for corpus-based interpreting teaching in light of Ecotranslatology. The new model of corpus-based interpreting teaching based on the Translation as Adaptation and Selection includes the introduction of interpreting theories; the training of interpreting skills; the cultivation the intercultural awareness of students; the development the communicative competence of students; the extracurricular practices, which explores a tentative research on interpreting teaching with an interdisciplinary approach.

\section{ACKNOWLEGEMENT}

*This project is supported by Hunan Provincial Funds (No.12YBA090, No.14B039, No.XYS13J45)

\section{REFERENCES}

[1] Hu, Gengshen. "Translation as Adaptation and Selection," Vol.4. Perspectives: Studies in ranslatology, 2003, pp 283-291.

[2] Hu, Gengshen. "Translator-centredness," Vol.2. Perspectives: Studies in Translatology, 2004, pp106-117.

[3] Seleskovitch, D. \& Lederer, M.. 1995. A Systematic Approach To Teaching, Interpretation. Trans. Jacolyn Harmer. Pairs: European communities, 1989.

[4] Eakins. Sex Difference in Nonverbal Communication, In Samover and Porter (ed.) Intercultural Communication: A Reader 5th ed. Wadsworth Publishing Co, 1982.

[5] Chen,Shengbai. An Ecological Approach to Interpretation Studies. Shanghai : Fudan University Press, 2013. 